\section{Centres of Learning}

In the last five years a large number of postgraduate medical centres and medical institutes have been set up in Britainand many more are being planned or are being built. Whether they are called centres or institutes, their objectives and the services they offer are similar. They set out to provide postgraduate and vocational training for hospital junior staff and continued education for established general practitioners and consultants in their area. They usually comprise a library, a lecture theatre, seminar rooms, offices for the clinical tutor and his secretary, and a variable amount of space and equipment for the provision of food and drink.

The Nuffield Provincial Hospitals Trust has shown its traditional capacity to recognize which new projects are likely to prove valuable by giving generous financial support to many medical centres. Local industry, private individuals, regional hospital boards, and medical men have been the other major contributors towards the cost of building. Most centres and institutes have been built as an appendage to general hospitals-an arrangement which has many functional and financial advantages. The land does not have to be purchased. Regional boards are happy for their architects to undertake the planning of the centre in consultation with local members of the profession. Hospital management committees are very willing to be responsible for heating, lighting, and maintenance, and in many instances the centre has been so planned that the hospital can also undertake the catering. For a centre to be used to the full it is essential that it should be easily accessible to those who use it, and an entrance from the hospital itself is obviously desirable.

Many of the largest and most successful centres and institutes have been established in populous areas with first-class hospitals where there would undoubtedly have been a medical school if the money were available to make it possible. Stoke-on-Trent, for example, is comparatively far from any medical school; its two main hospitals serve a large population and have formed several specialist units since the Health Service began. The North Staffordshire Medical Institute, ${ }^{1}$ which was opened at Stoke in 1965, has already gone far in its aim, stated in the appeal brochure, of " becoming a medical centre of national importance within the next 10 years." Moreover, the dramatic response to the appeal from all sections of the community showed that the spirit of pride in its local hospitals was not dead. Some other examples of centres that have partially filled the role of a medical school have recently been described in the series of articles by the B.M.F.'s special correspondent on "Aspects of Postgraduate Medicine"-and include the centres at Portsmouth" and Canterbury. $^{3}$ These centres have made the local circumstances even more fitting for the establishment of a medical school should the national economy permit.

Wherever a medical centre has been established it has undoubtedly improved the recruitment of hospital junior staff, raised the standard of hospital practice, and quickened the interest of local general practitioners in continued education. Nevertheless, however valuable the contributions of postgraduate medical centres has been, they have not been the only factor in improving postgraduate, vocational, and continuing medical education. Paramount among the other factors has been the transformation brought about in the regional hospitals. The latter are now staffed by consultants

\footnotetext{
Brit. med. 于., 1966, 2, 167

Ibid., 1966, 2, 45 .
}

who have had a similar training to those on the staff of university hospitals and who are anxious to teach, to do research, and to do clinical work of the highest standard. Their presence, their energy, and their enthusiasm have made many regional hospitals good vocational training centres for hospital junior staff, and local general practitioners now look to them to supply their continued educational needs.

Universities also have become very much more keenly aware of their responsibilities in the field of postgraduate medical education. They have given university status to the postgraduate clinical tutors in regional hospitals, and their postgraduate medical deans are increasingly active and anxious to stimulate postgraduate educational activity in their region. Nevertheless, as our special correspondent points out in his final article at p. 625 of this week's B.M.7., it is becoming increasingly desirable to set up some controlling influence to avoid reduplication and waste of effort. Whether the university or the regional board or both working in co-operation through a regional postgraduate committee should act in this way matters little-and clearly local circumstances are likely to make different patterns of administration desirable in different regions. But, as our correspondent shows, one arrangement that has worked very well is that in the Birmingham Region, and this might well serve as a suitable pattern for other regions to copy.

\section{Intrauterine Transfusion}

In recent years the early induction of delivery together with exchange transfusion in the newborn infant have done much to reduce the perinatal mortality from erythroblastosis foetalis. Once antibodies have developed in the mother it is impossible to control the haemolytic process in the foetus, and the latter may be affected as early as the second trimester. Even if the foetus is successfully delivered it is anaemic and treatment by exchange transfusion is not always successful.

The assessment of how badly the foetus is affected by determining the titre of rhesus anti-D antibodies in the maternal serum has not proved very reliable. The pioneer work of D. C. Bevis ${ }^{1}$ and A. W. Liley ${ }^{2}$ on spectrophotometric measurements of amniotic fluid has provided a method for assessing the condition of the foetus and for estimating the prognosis with remarkable accuracy. Thus presence of an increasing height of the wave of optical density in the amniotic fluid at the $450 \mathrm{~m} \mu$ wavelength has been shown to be related both to the severity of anaemia ${ }^{3}$ and to the prognosis. This increased height is probably due to the presence of several bile pigments and of albumin.

The ability to assess the state of the foetus led to attempts at treatment by intrauterine transfusion in very severely affected foetuses. In 1963 Liley $^{5}$ described a method in which blood was given into the peritoneal cavity of the foetus. The blood was absorbed rapidly by diapedesis of the cells into the capillaries. In this procedure the placenta and foetus were localized radiographically, and subsequently a needle was inserted through the mother's abdominal wall and the uterus, and finally into the peritoneal cavity of the foetus. A fine catheter was then passed through the needle, which was then withdrawn. In the case described by Liley two transfusions of $O$ rhesus-negative blood were required at 32 and 34 weeks of the pregnancy. A caesarean section was later carried out and an anaemic male child was delivered, who subsequently 
needed exchange transfusion. The child survived; without the intrauterine transfusions he would certainly have died.

Since then at least nine series of intraperitoneal intrauterine transfusions have been reported, ${ }^{6-12} 16$ and some 92 transfusions have been carried out with survival of 44 infants. The survival rate of only $50 \%$ must be viewed against a background of the virtually hopeless prognosis of the foetuses transfused. Nevertheless, as several authors have pointed out, $^{34}$ this procedure may be hazardous. Thus there are several instances of the foetus being killed by the procedure. Amnionitis and maternal peritonitis have been recorded, ${ }^{13}$ though there have been no maternal deaths. If the needle is to be positioned so that it avoids the foetal thorax or liver, the necessary radiographic examinations may mean a considerable exposure to radiation, and ideally the operation should be done under the control of an image intensifier. Small volumes of blood must be transfused slowly, and, since this is not an exchange transfusion, more than one transfusion may be necessary.

Another approach has been to cannulate a foetal vein or artery. In $1963 \mathrm{~V}$. J. Freda and K. Adamsons ${ }^{14}$ performed the first technically successful intrauterine exchange transfusion in a 33-year-old mother who was in the 27 th week of her pregnancy when the transfusion was carried out. Preliminary examination of the amniotic fluid showed that the foetus was severely affected by haemolytic disease. The placenta was localized with a technique using radioisotopes, and the abdomen and the uterus were then opened and a small incision made in the uterus opposite to a foetal foot. The membranes were not incised but freed so that they bulged out, with the foetal foot in them. The amniotic sac was opened and the foetal leg delivered as far as the groin, so that the femoral artery could be cannulated; $220 \mathrm{ml}$. of fresh $\mathrm{O}$ rhesusnegative blood was transfused. Both mother and foetus tolerated the procedure well, but two days after operation the child was born by precipitate delivery and died in the neonatal period from incomplete expansion of the lungs. S. Asensio and his colleagues ${ }^{15}$ are convinced that this is the most physiological method of supporting the foetus. They point out that it allows a larger quantity of blood to be transfused under controlled conditions, and that only one transfusion is necessary. They repeated the procedure using a modified technique-in particular they used the femoral vein for the transfusion. They were successful in delivering a Puerto Rican woman (gravida viii, para vi), who had no living children, of a live female infant.

Intrauterine exchange transfusion may prove to be a solution of the so-far intractable problem of the infant who is severely affected by haemolytic disease at an early stage of pregnancy. It raises a number of questions, including those

1 Bevis, D. C. A., Lancet, 1952, 1, 395

- Liley, A. W., Amer. F. Obstet. Gynec., 1961, 82, 1359

- Westberg. J. A., and Margolis, A. J., ibid., 1965, 92, 583.

- Bowes, W. A., Drose, V. E., and Bruns, P. D., ibid., 1965, 93, 822.

- Liley, A. W., Brit. med. F., 1963, 2, 1107.

- Obstet. and Gynec. Observer, 1964, 3, 1.

'Queenan, J. T., and Douglas, R. G., Obstet. and Gynec., 1965, 25, 308.

- Mandelbaum, Obst. and Gynec. Observer, 1964, 3, 1.

- Little, ibid., 1964, 3, 1 .

10 Holman, C. A., and Karnicki, J., Brit. med. F., 1964, 2, 594.

1 Oueenan, J. T., Obst. and Gynec. Observer, 1964, 3, 5.

". Queenan, J. T., Obst. and Gynec. Observer, 1964, 3, 5.

is Goodlin, R. C., Obstet. and Gynaec., 1965, 26, 803

1. Freda, V. J., and Adamsons, K., Amer. F. Obstet. Gynec., 1964, 89, 817.

to Asensio, S. H., Figueroa-Longo, J. G., and Pelegrina, I. A., ibid., 1966, 95, 1129.

- Gordon, H., Grausz, J. P., Raphael, M., and McClure Browne, J. C., 9. Obstet. Gynaec. Brit. Cwlth, 1966, 73, 917. of immunology. What effect does the transfusion of large quantities of foreign antigenic material have on the foetus? Could the use of fresh blood with viable lymphocytes result in the foetus being unable to reject the graft and the development of a graft-versus-host reaction? Washed, irradiated maternal cells may be found to be the most suitable for transfusion, while the low level of immunoglobulin IgGwhich may be seen in premature infants-will probably be found to be more severe in these foetuses and may require the administration of gammaglobulin routinely.

Studies of the foetus carried out at the time of these procedures may help in the understanding of the pathology of hydrops. Much of the pioneer work in intrauterine transfusion has been done in Great Britain and New Zealand. It is to be hoped that the development of this technique and the further investigations-such as are being carried out at present at St. Bartholomew's Hospital in London-will meet with success.

\section{Identification by Hair}

Microscopical examination of hair has long been a useful aid to identification for forensic purposes. A recent procedure called activation analysis provides a chemical microscope with interesting possibilities. This technique entails the identification and measurement of radioactivity induced in a specimen -for example, by exposure to neutrons inside a nuclear reactor. It does not usually help in estimating the concentrations or molecular arrangements of major constituents, but it offers a sensitive way of estimating many trace elements. These may form a unique pattern for each individual, who may thus be identified by the pattern. Levels of trace elements depend on diet, environment, and influences which are not understood but may be classified as metabolic idiosyncrasy.

R. F. Coleman and colleagues at the Atomic Weapons Research Establishment, Aldermaston, have made an extensive survey ${ }^{1}$ of the trace elements in human head hair using samples supplied by more than 800 people chosen at random from the electoral registers of England and Wales. Each hair was washed, irradiated in a nuclear reactor, and examined with a scintillation counter. This gave a record of the induced radioactivity. Concentrations of twelve elements were measured and subjected to statistical analysis in which allowance was made for variations of concentration among hairs from a single head. It was found that levels of trace elements showed large differences from person to person. The differences in samples from male and female subjects were large enough to allow the sex of the owners of about $90 \%$ of unknown hairs to be correctly determined by activation analysis.

In about $5 \%$ of the samples certain elements were present at unusually high levels owing to the occupation of the person. Though the hairs were thoroughly washed before analysis, copper levels were high in brassworkers, antimony in printers, and chromium in electroplaters. Other elements, including bromine and iodine, were derived from substances (neutralizers) used in permanent waving or cosmetic preparations High values of calcium were associated with hard-water areas and of manganese with the north of England-possibly because of a greater consumption of tea there than elsewhere.

Coleman, R. F., Cripps, F. H., Stimson, A., and Scott, H. D., Atom, $1967,123,12$. 